\title{
Article \\ Hybrid Sol-Gel Surface-Enhanced Raman Sensor for Xylene Detection in Solution
}

\author{
Verena Weber $^{1}$, Laura Brigo ${ }^{2} \mathbb{D}$, Giovanna Brusatin ${ }^{2}$, Giovanni Mattei ${ }^{3}$, Danilo Pedron ${ }^{1,4}$, Roberto Pilot ${ }^{1,4} \mathbb{D}$ \\ and Raffaella Signorini $1,4, * \mathbb{D}$ \\ 1 Department of Chemical Science, University of Padua, Via Marzolo 1, I-35131 Padova, Italy; \\ verena.weber@unipd.it (V.W.); danilo.pedron@unipd.it (D.P.); roberto.pilot@unipd.it (R.P.) \\ 2 Department of Industrial Engineering, University of Padua, Via Marzolo 9, I-35131 Padova, Italy; \\ laurabrigo@gmail.com (L.B.); giovanna.brusatin@unipd.it (G.B.) \\ 3 Department of Physics and Astronomy "Galileo Galilei", University of Padua, Via Marzolo 8, I-35131 Padova, \\ Italy; giovanni.mattei@unipd.it \\ 4 Consorzio INSTM, Via G. Giusti 12, I-50121 Firenze, Italy \\ * Correspondence: raffaella.signorini@unipd.it
}

check for updates

Citation: Weber, V.; Brigo, L.;

Brusatin, G.; Mattei, G.; Pedron, D.; Pilot, R.; Signorini, R. Hybrid Sol-Gel Surface-Enhanced Raman Sensor for Xylene Detection in Solution. Sensors 2021, 21, 7912. https://doi.org/ $10.3390 / \mathrm{s} 21237912$

Academic Editor: Huangxian Ju

Received: 22 October 2021

Accepted: 24 November 2021

Published: 27 November 2021

Publisher's Note: MDPI stays neutral with regard to jurisdictional claims in published maps and institutional affiliations.

Copyright: (c) 2021 by the authors. Licensee MDPI, Basel, Switzerland. This article is an open access article distributed under the terms and conditions of the Creative Commons Attribution (CC BY) license (https:/ / creativecommons.org/licenses/by/ $4.0 /)$.

\begin{abstract}
This paper reports on the fabrication and characterization of a plasmonic/sol-gel sensor for the detection of aromatic molecules. The sol-gel film was engineered using polysilsesquioxanes groups to capture the analyte, through $\pi-\pi$ interaction, and to concentrate it close to the plasmonic surface, where Raman amplification occurs. Xylene was chosen as an analyte to test the sensor. It belongs to the general class of volatile organic compounds and can be found in water or in the atmosphere as pollutants released from a variety of processes; its detection with SERS is typically challenging, due to its low affinity toward metallic surfaces. The identification of xylene was verified in comparison with that of other aromatic molecules, such as benzene and toluene. Investigations were carried out on solutions of xylene in cyclohexane, using concentrations in the range from 0 to $800 \mathrm{mM}$, to evaluate the limit of detection (LOD) of about $40 \mathrm{mM}$.
\end{abstract}

Keywords: xylene; SERS sensor; nanostructures; sol-gel film

\section{Introduction}

Surface enhanced Raman scattering (SERS) has been attracting much attention in the scientific community, especially in the field of chemical sensing, owing to its intrinsic high sensitivity and molecular specificity [1,2]. It has been successfully applied in different fields for the detection of materials such as explosives [3,4], toxic industrial chemicals [5], food contaminants and preservatives [6,7], biomolecules [8], bacteria [9], and dyes in works of $\operatorname{art}[10]$.

Volatile organic compounds (VOCs), in particular benzene, toluene and xylene (BTX), are a class of pollutants that require close monitoring due to their well-documented toxicity and widespread diffusion in the environment [11]. BTX are commonly used in the chemical industry for the production of many substances such as plastics, fibers, detergents, pesticides, paints, etc. [12]. BTX can contaminate water and soil as a consequence of accidental or fraudulent release of industrial waste, oil and gas extraction, leakage from underground storage tanks and so on [13]; importantly, they are also responsible for air pollution, as they can be released from combustion engines, industrial processes, and solvent use [14].

Ultra-sensitive and selective detection of toxic VOCs in traces is essential for environmental sustainability and human health. The measurement of VOCs, together with their identification, in the gaseous or liquid phase, is a challenging task that has been exploited with many different techniques. As an example, packed column gas chromatography has been combined with NMR techniques for the estimation of benzene and heavier aromatics in commercial gasoline [15]; solid-phase microextraction technique, followed by gas 
chromatography-mass spectrometry separation and detection, has been used for the determination of polycyclic aromatic hydrocarbons and benzene, toluene, ethylbenzene and xylene in snow water and water samples $[16,17]$. In addition, new methods, one based on the extraction solvent and combined with liquid chromatography [18], the second based on solid phase microextraction and combined with ultraviolet absorption spectroscopy, were employed to detect aromatic hydrocarbons in water [19]. All of these methods have high sensitivity and selectivity, but are costly and cannot be tailored for real-time analysis in the field. Only recently a development of a hand-portable system based on liquid chromatography incorporating a spectrally wide absorption detector was reported for the detection of polycyclic aromatic hydrocarbon mixtures [20]. A different approach is based on the detection of organic vapors through the observation of the Localized Surface Plasmon Resonance (LSPR) band of different nanostructures [21-23]. These sensors reveal the presence of organic compounds due to the variation of absorbance intensity, wavelength position, or bandwidth in the UV-VIS absorption spectrum of the plasmonic nanostructure. Although these works reported low detection limits (LODs) and high selectivity, the drawback of exploiting the LSPR band remains the indirect detection of the analyte: the variation of the plasmonic property is observed and is not directly a property of the analyte species. To overcome this drawback, SERS could be an interesting alternative detection technique. Only a few publications in the literature reported SERS experiments for the detection of organic compounds and the detection of VOCs [24-31].

In order to improve the selectivity and/or sensibility in SERS detection experiment, the affinity of the analytes to the substrate is often improved in several ways: for example, by functionalizing their surface with suitable receptors, by using aptamers or molecular imprint polymers [32], diazonium salt [33], polydimethylsiloxane (PDMS) [27], hydrophobic sponges [28], and metal-organic frameworks (MOFs) [34]. In addition, hybrid organicinorganic sol-gel films have been proposed for separation and sensing applications [35,36]. In particular, bridged polysilsesquioxanes are an interesting class of versatile functional materials: by changing the bridged compound, one can exploit many different functional groups, ranging from disulfides to aromatics and ureic groups, showing affinity to different analytes. These polysilsesquioxanes have been exploited as VOC adsorbents [28,37]. The use of polysilsesquioxanes for the detection of VOC has also been tested, through LSPR in coated substrates [38]. Moreover, the use of hybrid sol-gel materials allows for fine-tuning of the porosity of the final films [39].

In this work, a new plasmonic/sol-gel sensor was developed for the selective detection of xylene. A novel SERS sensing strategy is here proposed; it is based on the interaction of VOC molecules with a hybrid organic/inorganic sol-gel film, in order to avoid timeconsuming extraction techniques and obtain a high selectivity. The active structure is prepared by assembling core-shell (silica-gold) nanoparticles (NPs) on a glass substrate, functionalized with a silane molecule. On top of the SERS substrate, a thin hybrid organicinorganic sol-gel layer is spin-coated: the sol-gel coating is synthesized from a precursor bearing a diphenyl moiety, which is expected to capture aromatic compounds through $\pi-\pi$ interactions. The idea of coupling the sol-gel with the plasmonic substrate opens the way to a new class of sensors, whose affinity toward different analytes can be suitably tuned by properly choosing the characteristics of the sol-gel precursors. The plasmonic/sol-gel substrate is simple, easy to realize, and very versatile. It is demonstrated that it allows one to clearly distinguish xylene from other molecules of small aromatics, like benzene, with a promising detection limit (LOD), measured in cyclohexane solutions. The obtained results, in terms of LOD, are not yet competitive with other reported results in the literature, but leave the way open to further developments and exploitation.

\section{Materials and Methods}

\subsection{Chemicals}

Gold (III) chloride solution 30\% w / w in dilute $\mathrm{HCl}$ (CAS 16903-35-8), silver nitrate (CAS 7761-88-8), silver acetate (CAS 563-63-3), sodium citrate dihydrate (CAS 6132-04- 
3), Tetraethyl orthosilicate (TEOS) (CAS 78-10-4), Tetrakis(hydroxymethyl)phosphonium $80 \%$ in water (THPC) (CAS 124-64-1), (3-Aminopropyl)trimethoxysilane (APTMS) (CAS 13822-56-5), Tetraoctylammonium bromide (CAS 14866-33-2), sodium borohydride (CAS 16940-66-2), formaldehyde solution (CAS 50-00-0), potassium carbonate (CAS 584-087), 1-Dodecanethiol (CAS 112-55-0) and Polyvinylpyrrolidone (average mol wt 40,000) (CAS 9003-39-8), thiophenol (or benzenethiol) (CAS 108-98-5), para-xylene (CAS 106-42-3), purchased from Sigma-Aldrich, m-PEG-SH (mol wt 2000) (CAS 134874-49-0), Laysan Bio Inc., and bis(triethoxysilyl)biphenyl polysilsesquioxanes, (CAS 123640-93-7), $\mathrm{H}_{2} \mathrm{SO}_{4}$ (CAS 7664-93-9), $\mathrm{NH}_{4} \mathrm{OH}$ (CAS 1336-21-6), $\mathrm{H} 2 \mathrm{O} 2$ (CAS 7722-84-1) purchased from Sigma-Aldrich $(96 \%)$, are used without further purification. Soda lime cover slip glasses were purchased from Thermo Scientific. The synthesis was carried out in Milli- $Q$ deionized filtered water or in toluene (CAS 108-88-3).

\subsection{Synthesis of Materials}

\subsubsection{Synthesis of Nanoparticles and Nanoshells}

$\mathrm{Au}$ NPs in aqueous solution were synthesized using the citrate Turkevich method [40]: $1 \mathrm{~mL}$ of a $39 \mathrm{mM}$ aqueous solution of sodium citrate was added to $9 \mathrm{~mL}$ of a $1 \mathrm{mM}$ solution of gold (III) chloride $30 \% \mathrm{w} / \mathrm{w}$ in dilute $\mathrm{HCl}$, under reflux conditions, at $25^{\circ} \mathrm{C}$. The reaction was kept for $30 \mathrm{~min}$ under vigorous stirring.

Gold nanoshells (NSs) were prepared with a silica core and a gold shell [41]. The silica particles were synthesized using the Stöber method [42], based on sol-gel chemistry. An amount of $2 \mathrm{~mL}$ of $30 \%$ ammonium hydroxide solution was added to $50 \mathrm{~mL}$ of ethanol, under vigorous stirring, and then $1.5 \mathrm{~mL}$ of TEOS was slowly and dropwise added. The reaction mixture was kept overnight under stirring. For the functionalization of silica particles with APTMS, $10 \mu \mathrm{l}$ of APTMS was added to $10 \mathrm{~mL}$ of NPs in ethanol and the solution was kept overnight stirring and heating at $80^{\circ} \mathrm{C}$. The solution $\left(\mathrm{SiO}_{2} @ \mathrm{APTMS}\right)$ was then purified by centrifugation and dispersed in ethanol. Small gold NPs for silica-APTMS functionalization were synthesized by adding to $4.5 \mathrm{~mL}$ milli-Q water, $50 \mu \mathrm{l}$ of a $1 \mathrm{M} \mathrm{NaOH}$ solution, and subsequently $0.1 \mathrm{~mL}$ of a $68 \mathrm{mM}$ THPC solution. The mixture was kept under vigorous stirring for $5 \mathrm{~min}$ and then $0.2 \mathrm{~mL}$ of a $1 \%$ aqueous $\mathrm{HAuCl}_{4}$ solution was quickly added. The final NS samples were prepared by adding $150 \mu \mathrm{L}$ of $\mathrm{SiO}_{2} @ \mathrm{APTMS} @ \mathrm{Au}$ to $8 \mathrm{~mL}$ of $\mathrm{HAuCl}_{4}$ solution and finally adding $50 \mu \mathrm{L}$ of formaldehyde.

\subsubsection{Fabrication of SERS Substrates}

Plasmonic substrates were prepared according to the scheme shown in Figure 1 [43,44].

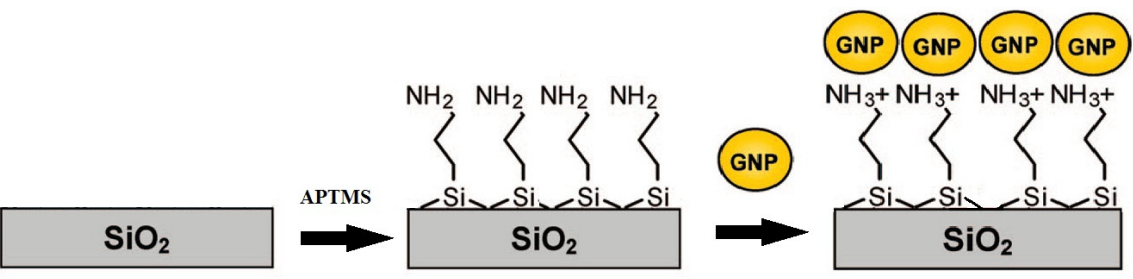

Figure 1. Scheme of the gold nanostructure deposition onto glass.

The glass slides were quickly cleaned with acetone, distilled water and finally with an acid piranha solution $\left(\mathrm{H}_{2} \mathrm{SO}_{3}: \mathrm{H}_{2} \mathrm{O}_{2} 3: 1\right)$ at $80^{\circ} \mathrm{C}$ for $1 \mathrm{~h}$. The slides were then rinsed in distilled water and cleaned one more time with basic piranha $\left(\mathrm{NH}_{4} \mathrm{OH}: \mathrm{H}_{2} \mathrm{O}_{2} 5: 1\right)$ at $80{ }^{\circ} \mathrm{C}$ for $20 \mathrm{~min}$. Their functionalization was accomplished by immersion in a $1 \%$ APTMS solution in toluene at $60^{\circ} \mathrm{C}$. The dried glasses were then immersed into a proper dilute colloidal nanostructure solution and kept at room temperature for 1 night, to allow the nanostructures to deposit onto the glass. The SERS substrates were finally cleaned with water to eliminate excess nanostructures on the substrate and stored in an inert environment. 


\subsubsection{Synthesis of the Sol-Gel Matrix}

The precursor used for the synthesis of the hybrid film was bis(triethoxysilyl)biphenyl polysilsesquioxanes (TEPS), whose molecular structure is depicted in Figure 2.

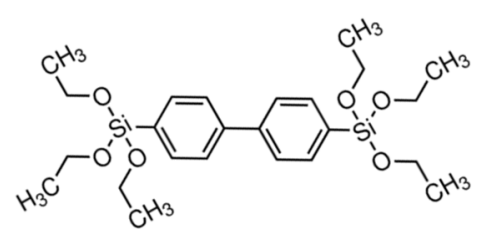

Figure 2. Molecular structure of bis(triethoxysilyl)biphenyl polysilsesquioxanes (TEPS), a precursor in sol-gel synthesis.

A solution of the sol-gel precursor, ethanol $(\mathrm{EtOH})$ and bidistilled water was mixed at room temperature in a 1/6 (molar ratio) precursor $/ \mathrm{H}_{2} \mathrm{O}$ mixture, using $1 \mathrm{~N}$ hydrochloric acid $(\mathrm{HCl})$ as the catalyst. The organic moiety in the hybrid network is specifically chosen for exhibiting a high-affinity interaction with aromatic hydrocarbons. Aromatic analyte molecules, penetrating into the porous sol-gel film, interact with the phenyl bridging groups of the organic unit by $\pi-\pi$ stacking interaction $[45,46]$. The use of these bridged silsesquioxane sol-gel precursors results in the realization of a film characterized by a pore volume fraction of 35\% [47], allowing the diffusion of small molecules.

The basic sol-gel synthesis is performed in the presence of $\mathrm{HCl}$ as an acidic catalyst and water in a 15 to $40 \mathrm{~g} / \mathrm{L}$ dilute sol solution of the precursor, depending on the desired final film thickness. The solution was then spin coated on a soda lime glass (about 2000-6000 rpm for 30-60 s) and subjected to a heat treatment of about $30 \mathrm{~min}$ at $60^{\circ} \mathrm{C}$. Through this method, already reported in the literature [38], films of thicknesses ranging from 50 to $300 \mathrm{~nm}$ could be obtained simply by varying the concentration of precursor solution and the spin coating parameters.

\subsection{Characterization Techniques}

2.3.1. UV-Vis Absorption Spectroscopy, Dynamic Light Scattering and Z-Potential Measurements

UV-Vis absorption spectroscopy spectra were collected with a Cary5 (Varian) spectrophotometer. All measurements were made in quartz cells with an optical path of 1 or $10 \mathrm{~mm}$. Dynamic Light Scattering (DLS) and Z-potential measurements were performed on NPs in solution with a Malvern Zetasizer Nano ZS with a $633 \mathrm{~nm}$ laser excitation.

\subsubsection{Raman}

Raman and SERS measurements were performed using a home-made Micro-Raman setup. A He-Ne laser, working at $633 \mathrm{~nm}$ (Melles Griot, output power $35 \mathrm{~mW}$ ), was used as an excitation light source. The laser beam was coupled to a microscope (Olympus BX 40) and focused on the sample using a $50 \times$ and a $20 \times$ objective (Olympus SLMPL, NA 0.75 and 0.4, respectively) for solid and liquid samples, respectively. The backscattered Raman signal was separated from the Rayleigh scattering by an edge filter and analyzed with a $320 \mathrm{~mm}$ focal length imaging spectrograph (TRIAX-320 ISA) and a liquid nitrogen-cooled CCD camera (Spectrum One, JobinYvon). The typical spot diameter at the focus was between 1 and $3 \mu \mathrm{m}$. The laser power on the samples ranged from 24 to $0.12 \mathrm{~mW}$.

\subsubsection{Atomic Force Microscopy}

The instrumentation used was an NT-MDT (NT- MDT-Europe B.V., Nuenen, the Netherlands) system, working in air with a piezoelectric scanner at $3 \mu \mathrm{m}$. The AFM images were analyzed with appropriate software, giving the NP dimensions. Measurements were made in tapping mode with a lock-in system to increase the signal-to-noise ratio. 


\subsubsection{Transmission Electron Microscopy}

Samples were prepared by putting some drops of NP solution on a copper grid. To prevent charge build-up at the sample surface, we coated the samples with a thin layer of conductive carbon material. The instrumentation used was a Field-Emission Gun (FEG) Tecnai F20 Super-twin (S)TEM (transmission electron microscopy) operating at $200 \mathrm{keV}$ and equipped with an EDAX (energy-dispersive X-ray spectrometer), a Gatan EELS (Electron energy loss spectrometer), and a scanning TEM attachment.

\section{Results and Discussion}

\subsection{Optical and Morphological Characterization of Nanoparticles, Nanoshells, and Substrates}

The synthesis of Au NPs is very reproducible, as demonstrated by the UV-Vis spectra of three different solutions, reported in Figure 3, showing good overlap. The stability of the Au NP solutions was also tested through Z-potential measurements: values of about $-40 /-45 \mathrm{mV}$ were obtained, confirming the high stability of these NPs in solution.

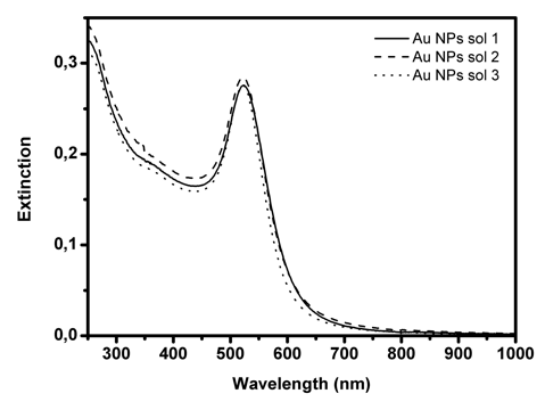

Figure 3. Extinction spectra of three different colloidal solutions of Au NPs.

By fitting the UV-Vis spectrum in solution, with the Mie-Gans relation, and extracting the extinction cross section [48], the dimension and concentration of Au NPs were estimated. The resulting diameter and concentration values are comparable to those derived from TEM measurements.

A first measurement of the particle radius was performed through dynamic light scattering, giving a hydrodynamic radius of $\mathrm{R} 1(\mathrm{DLS})=(58 \pm 8) \mathrm{nm}$. The radius of the TEM analysis returned a smaller radius of R1(TEM) $=(46 \pm 3) \mathrm{nm}$, as can be observed in Figure 4. The final concentration of NPs, calculated from the average diameter extracted by TEM analysis $(14 \mathrm{~nm})$, is approximately $7 \cdot 10^{12} \mathrm{NPs} / \mathrm{mL}$.

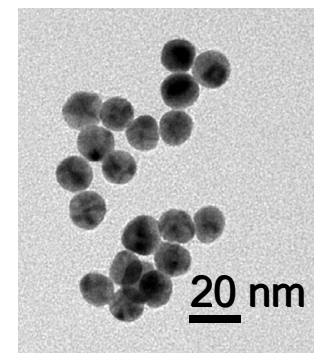

(a)

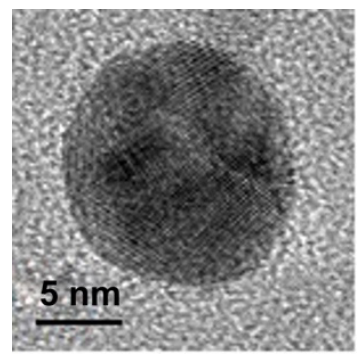

(b)

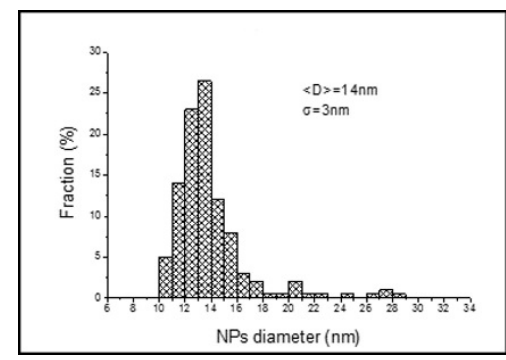

(c)

Figure 4. TEM image of a gold colloidal solution (a) $20 \mathrm{~nm}$ scale bar, with the zoom of a single NP (b), $5 \mathrm{~nm}$ scale bar, and histogram of the dimensional distribution (c).

The silica cores, used for the synthesis of NSs, present a very sharp distribution with a standard deviation of only $6.5 \%$ of the average radius, as observed from the TEM image in Figure $5 \mathrm{a}$ and its histogram distribution (b). EDX measurements on bare silica particles give $67 \%$ atomic presence of oxygen and 33\% of silica, as expected. Using the mean radius value of the TEM analysis, the concentration of the native silica NP solution was $1 \times 10^{13} \mathrm{NPs} / \mathrm{mL}$. 


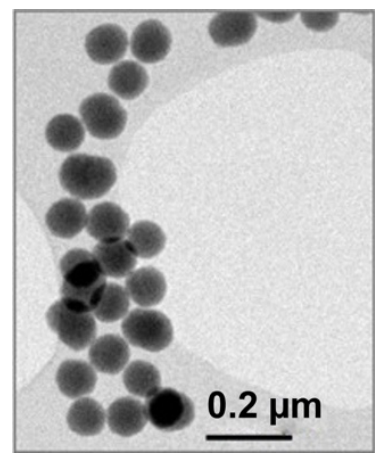

(a)

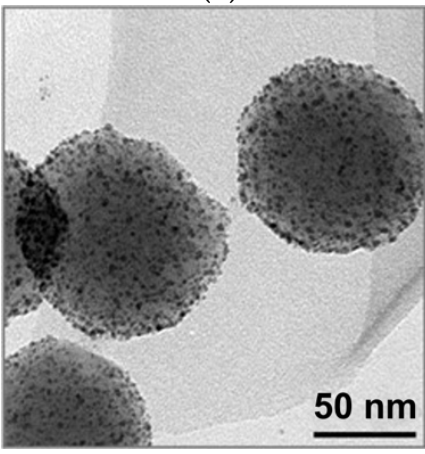

(c)

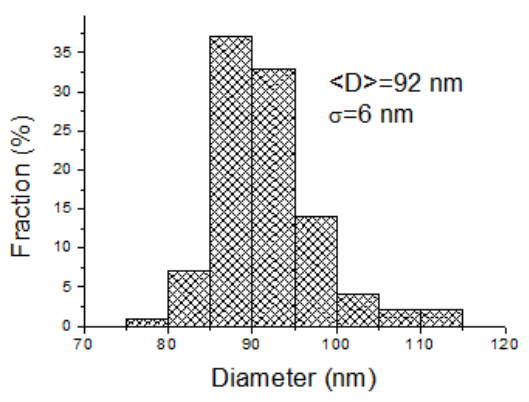

(b)

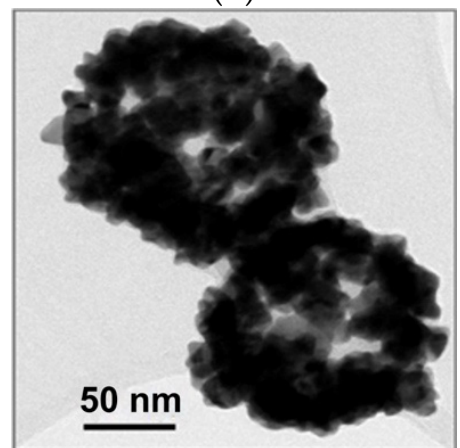

(d)

Figure 5. TEM analysis of bare $\mathrm{SiO} 2$ core NPs $(\mathrm{R} 1=46) \mathrm{NPs}(\mathrm{a})$ and histogram of the dimensional distribution (b). TEM images of SiO2@APTMS@Au (c) and Au NSs (R1 = 46; R2 = 65) (d).

The solution of small Au NPs obtained had a concentration of $4 \cdot 10^{14} \mathrm{NPs} / \mathrm{mL}$, calculated by estimating the radius of NPs $1 \mathrm{~nm}$. The homogeneous decoration of the silica cores with gold nuclei is visible in the TEM image of Figure $5 \mathrm{c}$.

From the difference between the measured NS radius and the SiO2@APTMS radius, the final shell thickness is calculated (R2). From the average TEM radius and the effective average shell thickness, the internal, R1, and the external, R2, NS radii were obtained (see Figure $5 \mathrm{c}$ and Table 1 ). Figure $5 \mathrm{~d}$ shows that the outer shell is partly incomplete.

Table 1. Radius and shell thickness values of $\mathrm{SiO}_{2} @ \mathrm{APTMS}$ and $\mathrm{Au}$ NSs samples.

\begin{tabular}{ccccc}
\hline Sample & Radius & $\begin{array}{c}\text { AFM Radius } \\
{[\mathbf{n m}]}\end{array}$ & $\begin{array}{c}\text { Shell Thickness } \\
{[\mathbf{n m}]}\end{array}$ & $\begin{array}{c}\text { TEM Radius } \\
\text { [nm] }\end{array}$ \\
\hline SiO2@APTMS & R1 & $61 \pm 5$ & - & $46 \pm 3$ \\
\hline Au NSs & R2 & $82 \pm 7$ & $21 \pm 9$ & $67 \pm 9$ \\
\hline
\end{tabular}

The $\mathrm{SiO}_{2} @$ APTMS particles were also analyzed by AFM; Figure 6a shows a high particle density, where the particles tend to aggregate in a hexagonal closed-packet conformation. However, particle diameters could be measured through appropriate software by extracting the nanoparticle profile, shown, as an example, in Figure 6a. From a statistical measurement of 10 profiles extracted from the AFM image, a particle dimension of $(122 \pm 11)$ nm was calculated.

The dimension estimated through AFM measurements is larger than the dimension measured through TEM. The reason is principally that the AFM images are influenced by the convolution of the AFM tip. For the NS sample, 10 profiles are extracted and the average diameter with its standard deviation is calculated. From the difference between the measured NS diameter and the SiO2@APTMS diameter, the shell thickness is calculated.

The UV-Vis-NIR spectra of different NS samples, obtained by adding different amounts of $\mathrm{SiO} 2(\mathrm{R} 1=38) @ A P T M S @ A u$ to the aged gold precursor solution, are shown in Figure 7. 


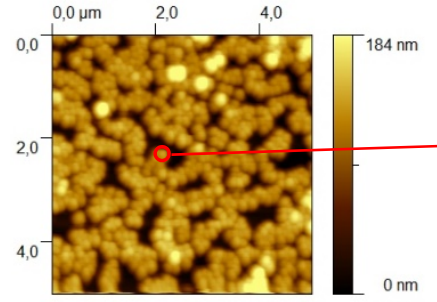

(a)

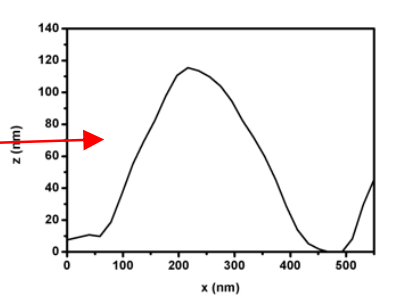

(b)

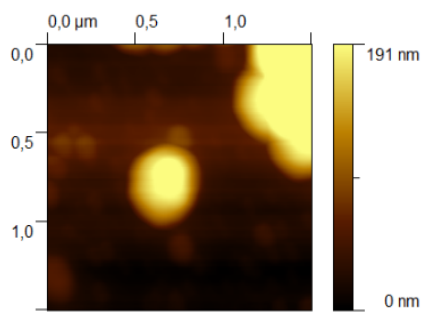

(c)

Figure 6. AFM images of the $\mathrm{SiO}_{2}(\mathrm{R} 1=46) @ \mathrm{APTMS}$ sample (a) and Au NSs (R1=46; R2=67) (c) and example of a single NP profile (b). The red arrow and the open circle indicate the particle chosen for profile extraction.

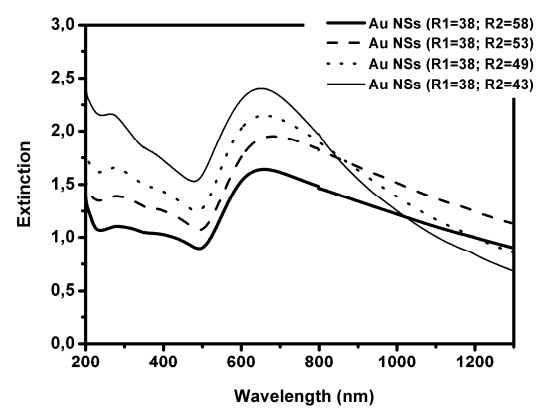

Figure 7. UV-Vis-NIR spectra of four different Au NSs (R1 = 38; R2 = x) samples.

In Au NSs (R1 = 46; R2 = y) samples a band, centered between 600 and $700 \mathrm{~nm}$, is present. This reflects the presence of an incomplete core-shell system [49] visible also in the TEM images in Figure 5d.

Both $\mathrm{Au}$ NPs and Au NSs were used to prepare substrates and exploit them for SERS sensing applications. The reproducibility of the plasmonic substrates was tested by preparing samples in the same experimental conditions and by checking their plasmonic resonance spectral position through UV-Vis spectroscopy. In Figure 8 the UV-Vis-NIR spectra of Au NPs and Au NSs (R1 = 38; R2 = 49) substrates are shown.

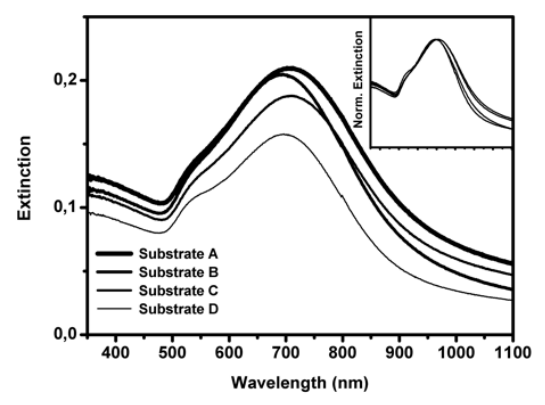

(a)

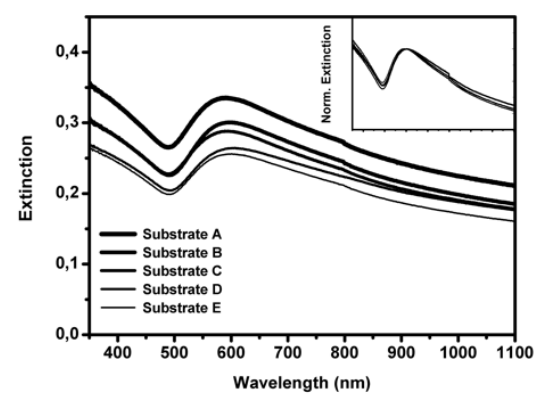

(b)

Figure 8. Extinction spectra of different Au NP substrates (a) and Au NS (R1 = 38; R2 = 49) substrates $(\mathrm{R} 1=38 ; \mathrm{R} 2=49)(\mathbf{b})$; normalized spectra in the insets.

The plasmonic extinction band of colloidal Au NPs was modified after deposition on a solid support. This is due to the formation of aggregates on the glass slide involving the presence of NP hot spots.

In the case of Au NS substrates, the realization of substrates at varying NS concentrations was tested through AFM. The AFM images on Au NS (R1 = 46; R2 = 69) substrates, realized with three different Au NS concentrations, are shown in Figure 9. 


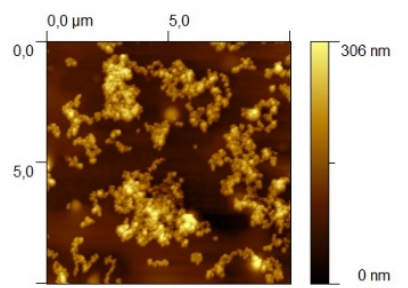

(a)

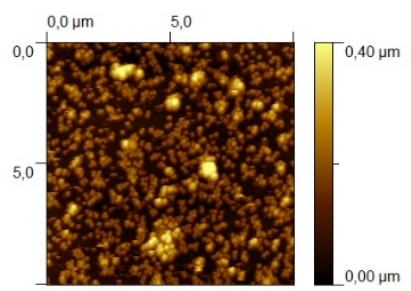

(b)

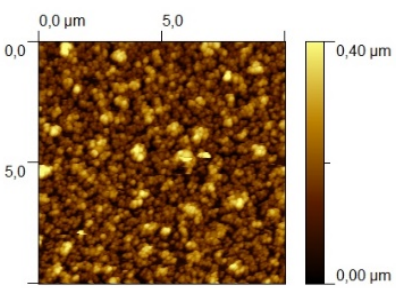

(c)

Figure 9. AFM images of Au NSs (R1 = 46; R2 = 69) substrates ( $R 1=46$; $22=69)$ with a coverage degree of about $20 \%($ a), $50 \%$ (b) and $70 \%$ (c).

From the AFM images, it can be observed that at higher coverage degrees the substrates appear more homogeneous. Therefore, the conditions for obtaining coverage degrees of about $70-75 \%$ were used for substrate realization.

The stability in the presence of different environments was checked by optical characterization in a phosphate buffer solution and in neutral and acidic methanol. The final stability test was performed after functionalization of the substrate with the analyte of interest. In Figure 10, a stability test is shown in a $1 \mathrm{mM}$ benzenethiol solution in methanol on Au NSs (R1 = 38; R2 = 49).

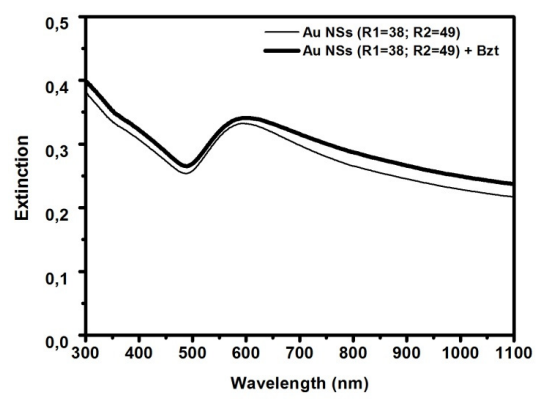

Figure 10. Extinction spectrum of Au NSs (R1 = 38; R2 = 49) before and after functionalization with benzenethiol.

As can be observed, the Au NS substrate is stable and does not undergo spectral modifications when immerged into a methanol solution.

Moreover, the substrates present a high homogeneity, already tested with AFM, and high optical quality, probed by optical microscope images and SERS measurements. Microscopy images of the Au NS and Au NP substrates, collected with a $50 \times$ objective, are reported in Figure 11: the high density of aggregates in the NP substrate and the homogeneity of the Au NS substrate are clearly visible.

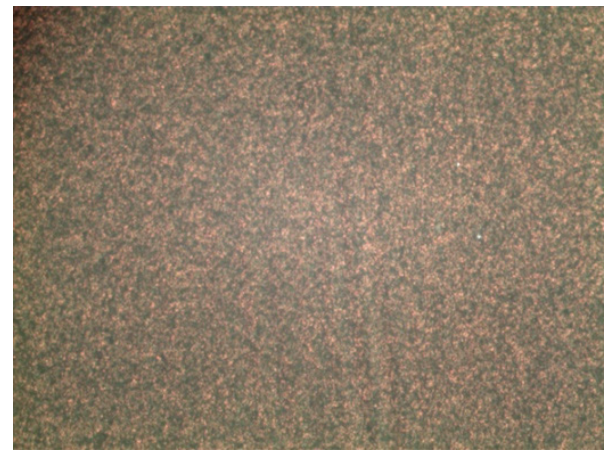

(a)

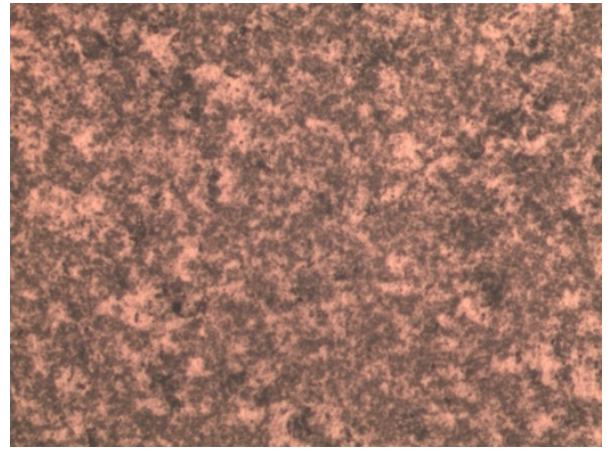

(b)

Figure 11. Microscopy images, collected with a $50 \times$ objective on the micro-Raman setup, of Au NSs (a) and Au NPs (b) substrates. 
The sol-gel films present a highly homogeneous pore distribution probed by AFM images and a reproducible thickness (Figure 12).

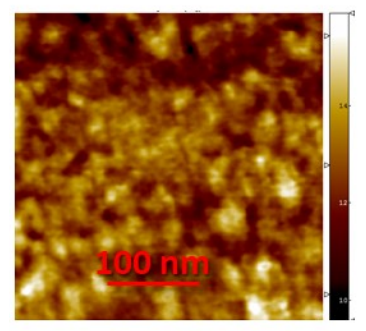

(a)

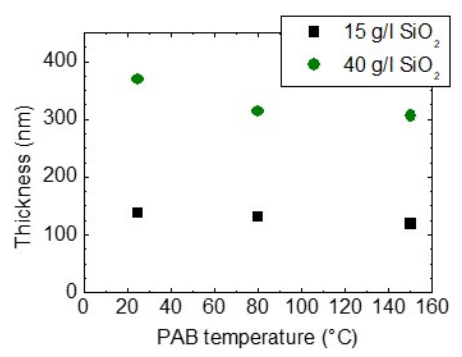

(b)

Figure 12. Morphological characterization of TEPS films: AFM image (a) and film thickness (b) as a function of heat treatment temperature at different sol dilutions.

The thickness of the sol-gel film was tested as a function of baking temperature: It can be observed that, depending on the amount of $\mathrm{SiO}_{2}$, higher post-application bake temperatures $(\mathrm{PAB})$ can also cause a decrease in film thickness.

\subsection{Raman Characterization of Materials and Substrates}

Before the SERS sensor was realized, a basic Raman characterization was performed on the matrix and different aromatic analytes, to identify the best spectral region for xylene detection, and the determination of the plasmonic enhancement was performed on SERS substrates.

In Figure 13a, the Raman spectra of the TEPS film and pure xylene, collected using $25 \mathrm{~mW}$ input power ( 3 spectra $\times 10$ s/spectrum), are compared.

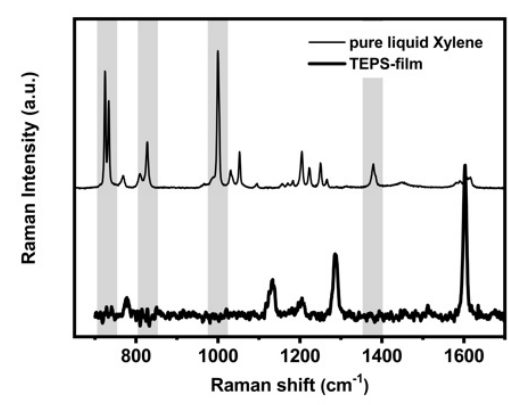

(a)

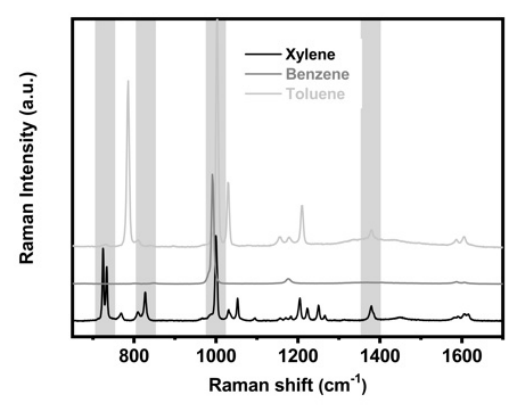

(b)

Figure 13. Raman spectra of the TEPS-film and of pure liquid xylene (a) and pure liquid xylene, toluene and benzene $(\mathbf{b})$ in the $650-1700 \mathrm{~cm}^{-1}$ region.

The Raman band positions and assignments are listed in Table 2. The grey regions show the signals of xylene (at 725-735, 810-827, 1000, and $1380 \mathrm{~cm}^{-1}$ ) that are not superimposed on the TEPS bands.

Table 2. Raman band position and assignment of pure xylene and TEPS-film.

\begin{tabular}{ccc}
\hline Raman Shift $\left(\mathbf{c m}^{-\mathbf{1}}\right)$ & $\begin{array}{c}\text { Xylene } \\
\text { Assignment } \\
{[50-52]}\end{array}$ & $\begin{array}{c}\text { TEPS-Film } \\
\text { Assignment } \\
{[37,38]}\end{array}$ \\
\hline $722-730$ & $v_{1}$ & $v_{\mathrm{s}}$ Si-C \\
\hline 780 & & \\
\hline $810-827$ & $v_{10 \mathrm{a}}$ & \\
\hline 997 & $v_{18 \mathrm{~b}}$ & \\
\hline
\end{tabular}


Table 2. Cont.

\begin{tabular}{|c|c|c|}
\hline Raman Shift $\left(\mathrm{cm}^{-1}\right)$ & $\begin{array}{c}\text { Xylene } \\
\text { Assignment } \\
{[50-52]}\end{array}$ & $\begin{array}{c}\text { TEPS-Film } \\
\text { Assignment } \\
{[37,38]}\end{array}$ \\
\hline 1030 & $v_{1 \mathrm{a}} v_{1 \mathrm{~b}}$ & \\
\hline 1050 & $v_{1 b}$ & \\
\hline 1132 & & $v_{\mathrm{s}} \mathrm{Si}-\mathrm{O}$ \\
\hline 1204 & $\begin{array}{l}\text { =C-H } \\
\text { Out of plane ring def. vib. }\end{array}$ & \\
\hline 1206 & & $\begin{array}{c}=\mathrm{C}-\mathrm{H} \\
\text { Out of plane ring def. vib }\end{array}$ \\
\hline 1223 & $v_{1 b}$ & \\
\hline 1250 & $\begin{array}{c}=\mathrm{C}-\mathrm{H} \\
\text { In plane ring def. vib. }\end{array}$ & \\
\hline 1286 & & $=\mathrm{C}-\mathrm{H}$ In plane ring def. vib. \\
\hline 1378 & $v_{\mathrm{s}} \mathrm{C}-\mathrm{H}$ (metyl) & \\
\hline 1602 & & $v_{\mathrm{S}} \mathrm{C}=\mathrm{C}$ \\
\hline
\end{tabular}

Furthermore, the comparison with the benzene and toluene spectra, collected using $25 \mathrm{~mW}$ input power (10 spectra $\times 10 \mathrm{~s} /$ spectrum) and reported in Figure $13 \mathrm{~b}$ (see Supplementary Materials for Raman band positions and the corresponding assignment), confirms the choice of the previous regions as characteristic for xylene detection.

Raman signal homogeneity and sensitivity (EF) measurements were tested on NP and NS substrates, using benzenethiol as the probe molecule for the measurement of the enhancement factor [53] (see Figure 14). Optimization of NP deposition concentrations and times led to a SERS signal reproducibility on a single substrate of up to $92 \%$, which is very good for substrates with randomly distributed NPs. The value of the enhancement factor of $(1.0 \pm 0.3) \times 10^{4}$ and $(3.0 \pm 0.3) \times 10^{4}$ for $633 \mathrm{~nm}$ excitation was evaluated, respectively, for the substrates NP and NS, by mapping the substrates at 10 random points [54] (see Supplementary Materials, Figure S1).

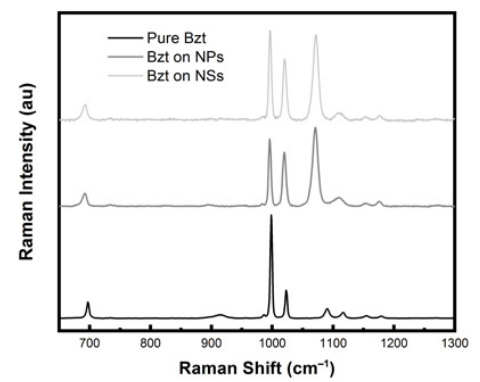

Figure 14. Raman spectrum of pure benzenethiol liquid and SERS spectra of benzenethiol adsorbed on NPs and NSs.

\subsection{Hybrid Sol Gel Matrix Spin Coated on Plasmonic Substrate}

The hybrid sol-gel matrix plays an important role in the approach of the aromatic molecules to the metallic interface and in overcoming the poor affinity in between aromatics and metals because of its porosity and the presence of bridged silsesquioxane precursors. The aromatic analyte molecules, which penetrate the porous sol-gel film, are able to interact with the phenyl bridging groups of the organic unit by $\pi-\pi$ stacking interaction [55].

For the detection of xylene, the first idea was to directly embed gold NPs into the sol gel matrix by adding them to the precursor solution during sol gel synthesis. 
Due to poor results, in terms of low amplification (reported in the Supplementary Materials), a different strategy was pursued: the sol-gel matrix was spin coated directly over the SERS substrate, forming the two-layer hybrid system, depicted in Figure 15. Here, the scheme of operation of the sensor is also described.
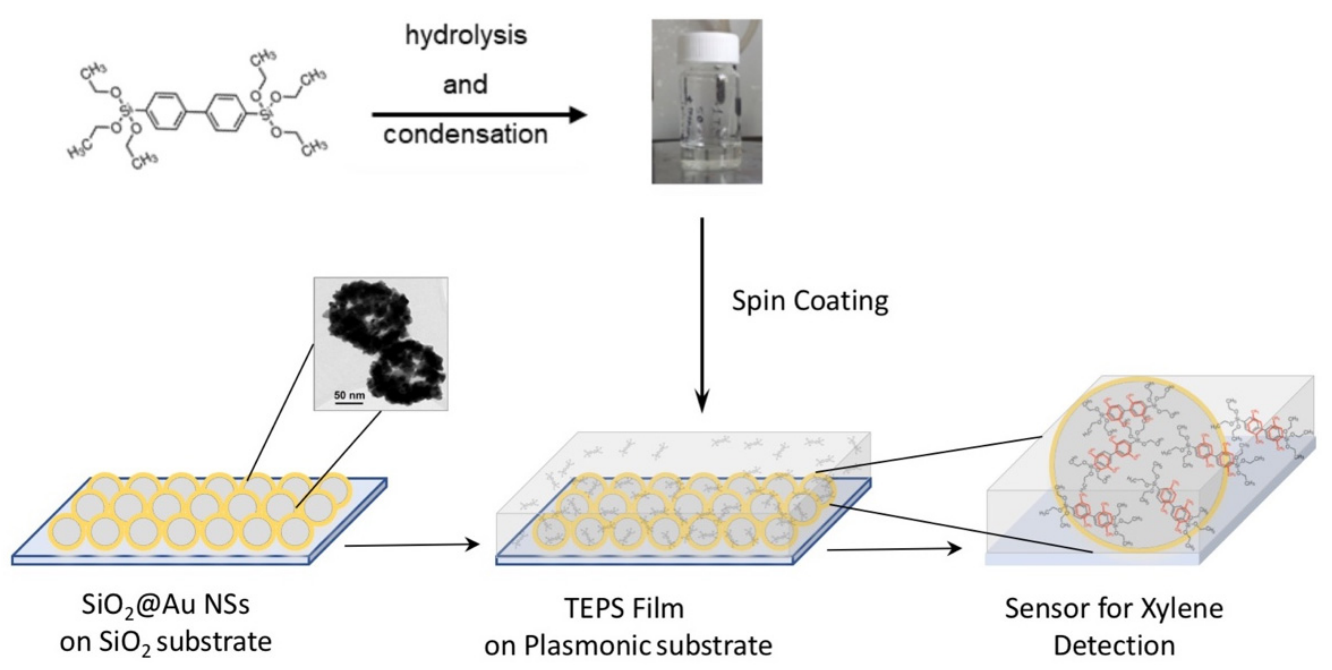

Figure 15. Scheme for the realization of the xylene SERS sensor.

The hybrid sol was spin coated on Au NP and Au NSs $(R 1=46 \mathrm{~nm}$; R2 = $67 \mathrm{~nm})$ substrates to obtain films of approximately $50 \mathrm{~nm}$ thickness. The extinction spectra of the samples with AuNSs are reported, as an example, in Figure 16.

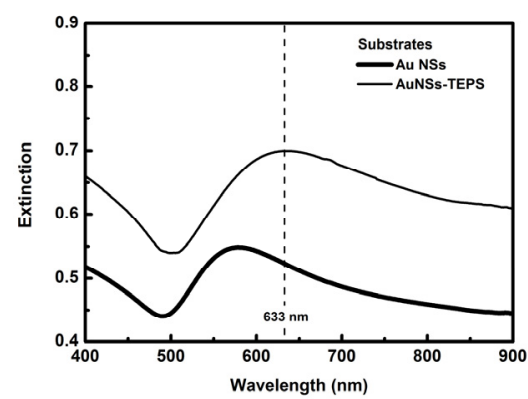

Figure 16. Extinction spectra of Au NSs substrate (thick black line) and AuNSs-TEPS film (thin black line) deposited on glass.

The extinction spectrum of the TEPS deposited on Au NSs substrates presents an increased intensity and a red shift with respect to the native Au NSs substrate. The plasmonic peak of the NSs, directly deposited on the glass substrates, is centered at $583 \mathrm{~nm}$, while it is shifted at $634 \mathrm{~nm}$ in the presence of TEPS films. This is due to the presence of the sol gel film, which possesses a higher refractive index with respect to the air. The two sensing substrates have been demonstrated to be reproducible in terms of extinction properties.

The TEPS substrates were tested using the micro-Raman setup and exciting the sample with $0.03 \mathrm{~mW}$ laser power; the collected Raman spectra are reported in Figure 17.

As can be observed, the matrix signals are clearly enhanced as a result of the presence of the plasmonic substrate. A TEPS film, of about $140 \mathrm{~nm}$ thickness, deposited onto a glass slide, does not give any Raman signal, while, at the same laser power, thinner TEPS films of $70 \mathrm{~nm}$, deposited on plasmonic substrates, show relatively strong Raman activity in the $1000-1600 \mathrm{~cm}^{-1}$ region. 


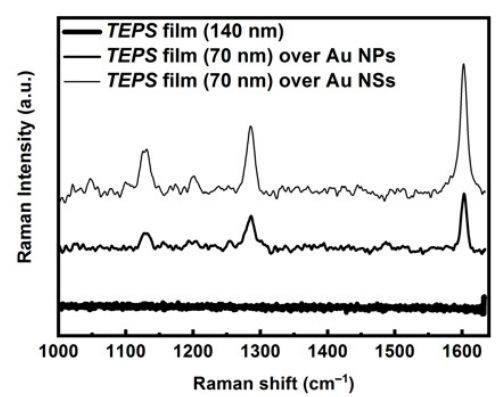

Figure 17. Raman and SERS spectra of TEPS film deposited on glass, Au NPs, and Au NSs substrates.

\subsection{Detection of Xylene}

Preliminary tests were performed incubating the Au NSs-TEPS substrates in pure liquid xylene or toluene in a closed detection setup. The collected Raman spectra (reported in Supplementary Materials) clearly show the characteristic Raman peaks of both aromatic molecules and allow the discrimination of xylene from toluene.

The enhancement efficiency of the plasmonic-sol-gel Au NSs-TEPS system was demonstrated by performing SERS measurements of substrates immersed in solutions of xylene in cyclohexane, enabling the investigation of a wide concentration range, from 0 to $800 \mathrm{mM}$.

In this experiment, the closed setup was used as a liquid cell: the AuNSs substrate was placed in the closed device, and the cell was filled with the organic solution and directly positioned under the SERS microscope. The collected spectra, recorded at an input laser power of $0.24 \mathrm{~mW}(20$ spectra $\times 10 \mathrm{~s} /$ spectrum $)$, are reported in Figure 18a.

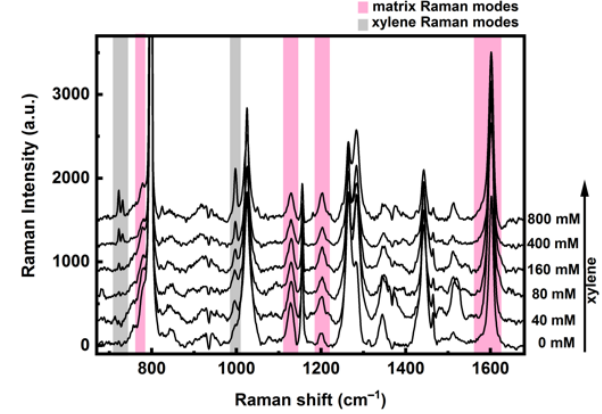

(a)

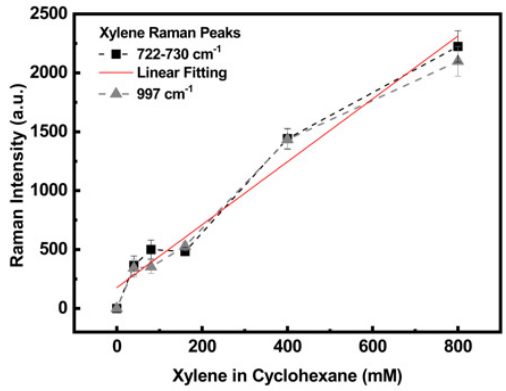

(b)

Figure 18. SERS spectra for the AuNSs-TEPS substrate in cyclohexane solution at different concentrations of xylene (a); evolution of the peak intensity of xylene as a function of concentration, with a linear fit of the signal $722-730 \mathrm{~cm}^{-1}(\mathbf{b})$.

SERS measurements at different concentrations of xylene in cyclohexane solution, ranging from 0 to $800 \mathrm{mM}$, are shown in Figure 18a. The signals evidenced in red are the Raman bands of the sol-gel matrix, the gray ones (at $722-730$ and $997 \mathrm{~cm}^{-1}$ ) are the more intense xylene bands, not superimposed with the matrix or cyclohexane, and the others (at 798, 1024, 1155, 1264, and $1442 \mathrm{~cm}^{-1}$ ) can be attributed to cyclohexane. The xylene bands at 722-730 and $997 \mathrm{~cm}^{-1}$ clearly emerge when increasing amounts of the analyte are added (spectra of 40 to $800 \mathrm{mM}$ ) and were used to evaluate the sensitivity of the realized system to the xylene concentration. To this end, the intensity of the xylene SERS bands is reported as a function of the xylene concentration, in Figure 18b, where the linear fit of the $722-730 \mathrm{~cm}^{-1}$ modes is also reported and shows a good linear dependence of the signal with the xylene concentration (Adj R-square of 0.96). This value is comparable to a SERS based Napthalene sensor [56] and is within the range of literature of other SERS sensors for polycyclic aromatic hydrocarbons [57], for food products [58] and for food contaminants [59]. 
From SERS data, we estimate a LOD of about $40 \mathrm{mM}$ xylene in cyclohexane. At this concentration, a comparison between the sensor (AuNSs-TEPS substrate), the naked plasmonic substrate (without TEPS) and a nonplasmonic substrate (TEPS film) was performed. The spectra of Figure 19 show an enhancement of the SERS signal due to the sensor design: the Au NSs substrate, without the sol-gel matrix, shows a good enhancement of the xylene Raman signal, but a further enhancement is obtained through the coupling between the plasmonic substrate and the sol-gel film. The values obtained from the integration of the Raman peak, at $995 \mathrm{~cm}^{-1}$, and reported in Table 3, show a signal that increases with the following ratios 1:7:14, going from the sol-gel film over a glass slide, to the NSs plasmonic film, to the coupled system.

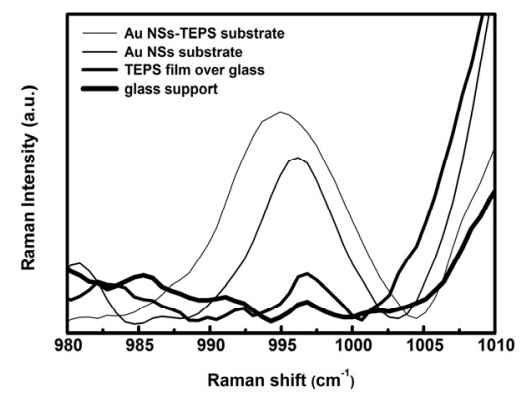

Figure 19. Spectral zoom in on the $995 \mathrm{~cm}^{-1}$ Raman band of xylene for four different substrates immersed into a $40 \mathrm{mM}$ xylene solution in cyclohexane.

Table 3. Peak frequency and peak area of the spectral zoom at $995 \mathrm{~cm}^{-1}$ for four different substrates immersed in a $40 \mathrm{mM}$ xylene solution in cyclohexane.

\begin{tabular}{ccc}
\hline Sample & Peak Frequency $\left[\mathrm{cm}^{-\mathbf{1}}\right]$ & Peak Area \\
\hline Au NSs-TEPS substrate & 995 & 1407 \\
\hline Au NSs substrate & 996 & 741 \\
\hline TEPS film & 997 & 107 \\
\hline Glass & 997 & 33 \\
\hline
\end{tabular}

Despite the good value of the SERS enhancement factor measured for the substrates, the LOD of xylene measured in this paper is quite high. For comparison purposes, Qian et al. measured, for toluene in solution, a LOD of $0.5 \mathrm{mM}$ with the bare SERS substrate and an LOD of $0.005 \mathrm{mM}$ adding a thin layer of PDMS on the substrate as a capture layer [27]; Jung et al. could separate and detect toluene and xylenes from a spiked water sample, at a concentration of around $2 \mathrm{mM}$ using silver nanowires coated with a hydrophobic capture layer (LOD was not determined) [28] (see Table 4).

Table 4. LOD of the VOC detected by SERS techniques.

\begin{tabular}{|c|c|c|c|}
\hline Analyte & SERS Substrate & LOD $[\mathrm{mM}]$ & Ref. \\
\hline \multirow{2}{*}{ Toluene } & Au NP monolayer & 0.5 & \multirow{2}{*}{ xxxiv } \\
\hline & Au NP monolayer/PDMS & 0.005 & \\
\hline Toluene, Xylene & Ag nanowires/hydrophobic sponge & n.d. & $\mathrm{xxxV}$ \\
\hline Xylene & Au NP monolayer/TEPS & 40 & This paper \\
\hline
\end{tabular}

Relatively high LODs are expected for analytes that do not possess an affinity for the metallic surface [34]; however, in our case, the capture layer, the TEPS film, improved the detection sensitivity only to a limited extent. We attribute this limit to different possible effects:

(a) The laser heats the sample, causing desorption of the xylene molecules from the matrix. Measurement of the temperature reached by the substrate upon illumination 
was carried out by looking at the Stokes / anti-Stokes ratio (see Supplementary Materials), revealing that $\mathrm{T}$ can vary from $60^{\circ} \mathrm{C}$ (laser power $8 \mu \mathrm{W}$ ) to $110^{\circ} \mathrm{C}$ (laser power $800 \mu \mathrm{W})$.

(b) The xylene molecules absorbed in the TEPS layer lie not so close to the hot spots in the plasmonic substrate, not allowing an efficient exploitation of the SERS enhancement of the substrate.

(c) The porosity of the TEPS layer could prevent the migration of the xylene molecules toward the plasmonic amplified region at the interface with the NSs.

(d) The heating induced desorption of xylene can be overcome by using a cooling system [31] and choosing a precursor of the sol-gel film characterized by a stronger affinity for xylenes.

In conclusion, the main advantages of this plasmonic sensor are the ability to distinguish different analytes (toluene, benzene, and xylene), the possibility of tuning the chemical composition of the matrix to make it more affine to different types of analytes, and the good enhancing properties of the SERS substrate. However, the overall sensitivity of this device still needs to be improved to make it effectively applicable to the detection of BTX in the water and/or gas phase.

\section{Conclusions}

The data presented and discussed above demonstrate that the sensor system developed herein, combining a SERS substrate with a porous hybrid film, shows interesting properties in terms of easy and inexpensive realization and enhanced efficiency.

The two separate components, the Au NS substrate and the TEPS film, are easy to prepare and assemble, and their single properties work together to realize a complex system with enhanced SERS activity. The Au NS substrate provides the enhanced local field to be exploited in SERS, while the TEPS film captures the analyte near the plasmonic surface.

Existing limitations of this system are probably due to the local heating of the sensor, which causes a fast desorption of the analyte from the diphenyl bridging group. This effect can be overcome by using a cooling system or by designing a new polysilsesquioxane system, which could show an increased interaction between the analyte and the matrix, such as a quinoide bridging group in the sol-gel system, that could provide energy transfer mechanisms.

The potentiality of this system was demonstrated with the detection of liquid xylene, showing that the identification of xylene is specific because it can also be distinguished from benzene and toluene, because of the use of the Raman technique, which gives a fingerprint signal of the analyte. Moreover, the quantification of the xylene, at low concentrations, down to $40 \mathrm{mM}$, is obtained with a simple and easy to realize detection setup, based on the local amplification of the Raman signal, through the plasmonic resonance of NSs. The use of these properly designed plasmonic NPs allows the plasmonic resonance to be tuned, thus increasing the amplification with respect to simple gold NPs. Finally, using sol-gel porous films coupled to the plasmonic substrate, it is possible to finely and easily tune the properties of the final device.

Therefore, we can conclude that the sensor works well in terms of the specific recognition of the analyte, and therefore, it shows good potential even if it presents a high LOD. The possibility of implementing its performance is linked, on the one hand, by the use of new metal particles with greater local amplification and, on the other, by the modulation of the specific properties of the sol-gel, using new precursors with enhanced affinity toward the aromatic groups.

Supplementary Materials: Available online at https:/ /www.mdpi.com/article/10.3390/s21237912/s1.

Author Contributions: Conceptualization, G.B., D.P. and R.S.; methodology, G.B., G.M., D.P. and R.S.; software, V.W. and R.P.; validation, V.W. and L.B.; formal analysis, V.W., R.P. and R.S.; investigation, V.W., L.B., R.P. and R.S.; resources, G.B., R.P. and R.S.; data curation, V.W., R.P. and R.S., writingoriginal draft preparation, R.P. and R.S.; writing—review and editing, D.P., G.B., G.M., R.P. and R.S.; 
visualization, D.P., G.B., G.M., R.P. and R.S.; supervision, G.B. and R.S.; project administration, G.B. and R.S.; funding acquisition, G.B., R.P., G.M., D.P. and R.S.. All authors have read and agreed to the published version of the manuscript.

Funding: This research was funded by the Department of Chemical Sciences of the University of Padova, project P-DiSC\#10BIRD2019-UNIPD.

Acknowledgments: The authors are grateful to Piero Schiavuta for support for AFM measurements.

Conflicts of Interest: The authors declare no conflict of interest.

\section{References}

1. $\quad$ Langer, J.; de Aberasturi, D.J.; Aizpurua, J.; Alvarez-Puebla, R.A.; Auguié, B.; Baumberg, J.J.; Bazan, G.C.; Bell, S.E.J.J.; Boisen, A.; Brolo, A.G.; et al. Present and future of surface-enhanced Raman scattering. ACS Nano 2020, 14, 28-117. [CrossRef]

2. Pilot, R.; Signorini, R.; Durante, C.; Orian, L.; Bhamidipati, M.; Fabris, L. A review on surface-enhanced raman scattering. Biosensors 2019, 9, 57. [CrossRef]

3. Hakonen, A.; Andersson, P.O.; Stenbæk Schmidt, M.; Rindzevicius, T.; Käll, M. Explosive and chemical threat detection by surface-enhanced Raman scattering: A review. Anal. Chim. Acta 2015, 893, 1-13. [CrossRef] [PubMed]

4. Gillibert, R.; Huang, J.Q.; Zhang, Y.; Fu, W.L.; Lamy de la Chapelle, M. Explosive detection by Surface Enhanced Raman Scattering. TrAC-Trends Anal. Chem. 2018, 105, 166-172. [CrossRef]

5. Ong, T.T.X.; Blanch, E.W.; Jones, O.A.H. Surface enhanced raman spectroscopy in environmental analysis, monitoring and assessment. Sci. Total Environ. 2020, 720, 137601. [CrossRef]

6. Ellis, D.I.; Muhamadali, H.; Haughey, S.A.; Elliott, C.T.; Goodacre, R. Point-and-shoot: Rapid quantitative detection methods for on-site food fraud analysis-Moving out of the laboratory and into the food supply chain. Anal. Methods 2015, 7, 9401-9414. [CrossRef]

7. Zheng, J.; He, L. Surface-enhanced raman spectroscopy for the chemical analysis of food. Compr. Rev. Food Sci. Food Saf. 2014, 13, 317-328. [CrossRef] [PubMed]

8. Cialla-May, D.; Zheng, X.-S.; Weber, K.; Popp, J. Recent progress in surface-enhanced Raman spectroscopy for biological and biomedical applications: From cells to clinics. Chem. Soc. Rev. 2017, 46, 3857-4112. [CrossRef]

9. Baumberg, J.; Bell, S.; Bonifacio, A.; Chikkaraddy, R.; Chisanga, M.; Corsetti, S.; Delfino, I.; Eremina, O.; Fasolato, C.; Faulds, K.; et al. SERS in biology/biomedical SERS: General discussion. Faraday Discuss. 2017, 205, 429-456. [CrossRef] [PubMed]

10. Casadio, F.; Leona, M.; Lombardi, J.R.; Van Duyne, R.P. Identification of organic colorants in fibers, paints, and glazes by surface enhanced raman spectroscopy. Acc. Chem. Res. 2010, 43, 782-791. [CrossRef] [PubMed]

11. Li, A.J.; Pal, V.K.; Kannan, K. A review of environmental occurrence, toxicity, biotransformation and biomonitoring of volatile organic compounds. Environ. Chem. Ecotoxicol. 2021, 3, 91-116. [CrossRef]

12. Sweeney, W.A.; Bryan, P.F. BTX processing. In Kirk-Othmer Encyclopedia of Chemical Technology; John Wiley \& Sons Inc.: Hoboken, NJ, USA, 2000. [CrossRef]

13. Tursi, A.; Chidichimo, F.; Bagetta, R.; Beneduci, A. BTX removal from open Aqueous systems by modified cellulose fibers and evaluation of competitive evaporation kinetics. Water 2020, 12, 3154. [CrossRef]

14. Masih, A.; Lall, A.S.; Taneja, A.; Singhvi, R.; Team, R.; States, U.; Protection, E. Exposure levels and health risk assessment of ambient BTX at urban and rural environments of a terai region of northern India. Env. Pollut. 2018, 242, 1678-1683. [CrossRef]

15. Singh, A.P.; Mukherji, S.; Tewari, A.K.; Kalsi, W.R.; Sarpal, A.S. Determination of benzene and total aromatics in commercial gasolines using packed column GC and NMR techniques. Fuel 2003, 82, 23-33. [CrossRef]

16. Sieg, K.; Fries, E.; Puttmann, W. Analysis of benzene, toluene, ethylbenzene, xylenes and n-aldehydes in melted snow water via solid-phase dynamic extraction combined with gas chromatography/mass spectrometry. J. Chromatogr. A 2008, 1178, 178-186. [CrossRef]

17. Bianchin, J.N.; Nardini, G.; Merib, J.; Dias, A.N.; Martendal, E.; Carasek, E. Simultaneous determination of polycyclic aromatic hydrocarbons and benzene, toluene, ethylbenzene and xylene in water samples using a new sampling strategy combining different extraction modes and temperatures in a single extraction solid-phase microextraction-gas chromatography-mass spectrometry procedure. J. Chromatogr. A 2012, 1233, 22-29. [CrossRef] [PubMed]

18. Sun, X.; Tan, J.; Ding, H.; Tan, X.; Xing, J.; Xing, L.; Zhai, Y.; Li, Z. Detection of polycyclic aromatic hydrocarbons in water samples by annular platform-supported ionic liquid-based headspace liquid-phase microextraction. J. Anal. Methods Chem. 2018, 2018, 3765682. [CrossRef] [PubMed]

19. Wittkamp, B.L.; Hawthorne, S.B.; Tilotta, D.C. Determination of Aromatic compounds in water by solid phase microextraction and ultraviolet absorption spectroscopy. Anal. Chem. 1997, 69, 1197-1203. [CrossRef]

20. Chatzimichail, S.; Rahimi, F.; Saifuddin, A.; Surman, A.J.; Taylor-Robinson, S.D.; Salehi-Reyhani, A. Hand-portable HPLC with broadband spectral detection enables analysis of complex polycyclic aromatic hydrocarbon mixtures. Comm. Chem. 2021, 4, 17. [CrossRef]

21. Cheng, C.S.; Chen, Y.Q.; Lu, C.J. Organic vapour sensing using localized surface plasmon resonance spectrum of metallic nanoparticles self assemble monolayer. Talanta 2007, 73, 358-365. [CrossRef] 
22. Chen, Y.Q.; Lu, C.J. Surface modification on silver nanoparticles for enhancing vapor selectivity of localized surface plasmon resonance sensors. Sens. Actuators B Chem. 2009, 135, 492-498. [CrossRef]

23. Chen, K.J.; Lu, C.J. A vapor sensor array using multiple localized surface plasmon resonance bands in a single UV-vis spectrum. Talanta 2010, 81, 1670-1675. [CrossRef] [PubMed]

24. Carron, K.; Peltersen, L.; Lewis, M. Octadecylthiol-modified surface-enhanced raman spectroscopy substrates: A new method for the detection of aromatic compounds. Environ. Sci. Technol. 1992, 26, 1950-1954. [CrossRef]

25. Mosier-Boss, P.A.; Lieberman, S.H. Detection of volatile organic compounds using surface enhanced Raman spectroscopy substrates mounted on a thermoelectric cooler. Anal. Chim. Acta 2003, 488, 15-23. [CrossRef]

26. Wittkamp, B.L.L.; Tilotta, D.C.C. Determination of BTEX compounds in water by solid-phase microextraction and Raman spectroscopy. Anal. Chem. 1995, 67, 600-605. [CrossRef]

27. Qian, C.; Guo, Q.; Xu, M.; Yuan, Y.; Yao, J. Improving the SERS detection sensitivity of aromatic molecules by a PDMS-coated Au nanoparticle monolayer film. RSC Adv. 2015, 5, 53306-53312. [CrossRef]

28. Jung, H.S.; Koh, E.H.; Mun, C.W.; Min, J.; Sohng, W.; Chung, H.; Yang, J.Y.; Lee, S.; Kim, H.J.; Park, S.G.; et al. Hydrophobic hBN-coated surface-enhanced Raman scattering sponge sensor for simultaneous separation and detection of organic pollutants. J. Mater. Chem. C 2019, 7, 13059-13069. [CrossRef]

29. Xia, D.; Guo, Q.; Ge, M.; Yuan, Y.; Xu, M.; Yao, J. On-line sensitive detection of aromatic vapor through PDMS/C3H7S-assisted SERS amplification. RSC Adv. 2016, 6, 53289-53295. [CrossRef]

30. Men, D.; Feng, S.; Liu, G.; Hang, L.; Zhang, T. A sensitive "optical nose" for detection of volatile organic molecules based on Au@MOFs nanoparticle arrays through surface-enhanced raman scattering. Part. Part. Syst. Charact. 2020, 37, 1-8. [CrossRef]

31. Oh, M.K.; De, R.; Yim, S.Y. Highly sensitive VOC gas sensor employing deep cooling of SERS film. J. Raman Spectrosc. 2018, 49, 800-809. [CrossRef]

32. Zhang, Y.; Zhao, S.; Zheng, J.; He, L. Surface-enhanced Raman spectroscopy (SERS) combined techniques for high-performance detection and characterization. Trends Anal. Chem. 2017, 90,1-13. [CrossRef]

33. Tijunelyte, I.; Betelu, S.; Moreau, J.; Ignatiadis, I.; Berho, C.; Lidgi-Guigui, N.; Guénin, E.; David, C.; Vergnole, S.; Rinnert, E.; et al. Diazonium salt-based surface-enhanced raman spectroscopy nanosensor: Detection and quantitation of aromatic hydrocarbons in water samples. Sensors 2017, 17, 1198. [CrossRef]

34. Kreno, L.E.; Greeneltch, N.G.; Farha, O.K.; Hupp, J.T.; Van Duyne, R.P. SERS of molecules that do not adsorb on Ag surfaces: A metal-organic framework-based functionalization strategy. Analyst 2014, 139, 4073-4080. [CrossRef]

35. Guizard, C.; Bac, A.; Barboiu, M.; Hovnanian, N. Hybrid organic-inorganic membranes with specific transport properties: Application in separation and sensors technologies. Sep. Purif. Technol. 2001, 25, 167-180. [CrossRef]

36. Shea, K.J.; Loy, D.A. Bridged polysilsesquioxanes. molecular-engineered hybrid organic-Inorganic materials. Chem. Mater. 2001, 13, 3306-3319. [CrossRef]

37. Dabrowski, A.; Barczak, M.; Robens, E.; Stolyarchuk, N.V.; Yurchenko, G.R.; Matkovskii, O.K.; Zub, Y.L. Ethylene and phenylene bridged polysilsesquioxanes functionalized by amine and thiol groups as adsorbents of volatile organic compounds. Appl. Surf. Sci. 2007, 253, 5747-5751. [CrossRef]

38. Brigo, L.; Cittadini, M.; Artiglia, L.; Rizzi, G.A.; Granozzi, G.; Guglielmi, M.; Martucci, A.; Brusatin, G. Xylene sensing properties of aryl-bridged polysilsesquioxane thin films coupled to gold nanoparticles. J. Mater. Chem. C 2013, 1, 4252-4260. [CrossRef]

39. Ishizaki, K.; Komarneni, S.; Nanko, M. Sol-gel processing, designing porosity, pore size and polarity, and shaping processes. In Porous Materials. Materials Technology Series; Springer: Boston, MA, USA, 1998; Volume 4. [CrossRef]

40. Turkevich, J.; Stevenson, P.C.; Hillier, J. The formation of colloidal gold. J. Phys. Chem. 1953, 57, 670-673. [CrossRef]

41. Oldenburg, S.J.; Averitt, R.; Westcott, S.L.; Halas, N.J. Nanoengineering of optical resonances. Chem. Phys. Lett. 1998, $288,243-247$. [CrossRef]

42. Stober, W.; Fink, A.; Bohn, E. Controlled growth of monodisperse silica spheres in the micron size range. J. Colloid Interface Sci. 1967, 26, 62-69. [CrossRef]

43. Freeman, R.G.; Grabar, K.C.; Allison, K.J.; Bright, R.M.; Davis, J.A.; Guthrie, A.P.; Hommer, M.B.; Jackson, M.A.; Smith, P.C.; Walter, D.G.; et al. Self-assembled metal colloid monolayers: An approach to sers substrates. Science 1995, 267, 1629-1632. [CrossRef]

44. Grabar, K.C.; Freeman, R.G.; Hommer, M.B.; Natan, M.J. Preparation and characterization of Au colloid monolayers. Anal. Chem. 1995, 67, 735-743. [CrossRef]

45. Brigo, L.; Gazzola, E.; Cittadini, M.; Zilio, P.; Zacco, G.; Romanato, F.; Martucci, A.; Guglielmi, M.; Brusatin, G. Short and long range surface plasmon polariton waveguides for xylene sensing. Nanotechnology 2013, 24, 155502. [CrossRef]

46. Burleigh, M.C.; Markowitz, M.A.; Spector, M.S.; Gaber, B.P. Porous polysilsesquioxanes for the adsorption of phenols. Environ. Sci. Technol. 2002, 36, 2515-2518. [CrossRef]

47. Brigo, L.; Faustini, M.; Pistore, A.; Kang, H.K.; Ferraris, C.; Schutzmann, S.; Brusatin, G. Porous inorganic thin films from bridged silsesquioxane sol-gel precursors. J. Non. Cryst. Solids 2016, 432, 399-405. [CrossRef]

48. Amendola, V.; Meneghetti, M. Size evaluation of gold nanoparticles by UV-vis spectroscopy. J. Phys. Chem. C 2009, 113, 4277-4285. [CrossRef]

49. Preston, T.C.; Signorell, R. Growth and optical properties of gold nanoshells prior to the formation of a continuous metallic layer. ACS Nano 2009, 3, 3696-3706. [CrossRef] [PubMed] 
50. Socrates, G. Infrared E Raman Characteristic Group Frequencies: Tables E Charts; John Wiley and Sons: Chichester, UK, 2001.

51. Varsanyi, G. Vibrational Spectra of Benzene Derivatives; Academic Press: New York, NY, USA; London, UK, 1969.

52. Wilmshurst, J.K.; Bernstein, H.J. The infrared and Raman spectra of toluene, toluene-a-d3, m-xylene, and m-xylene-aa'-d6. Can. J. Chem. 1957, 35, 911-925. [CrossRef]

53. McFarland, A.D.; Young, M.A.; Dieringer, J.A.; Van Duyne, R.P. Wavelength-scanned surface-enhanced Raman excitation spectroscopy. J. Phys. Chem. B 2005, 109, 11279-11285. [CrossRef] [PubMed]

54. Weber, V.; Feis, A.; Gellini, C.; Pilot, R.; Salvi, P.R.; Signorini, R. Far- and near-field properties of gold nanoshells studied by photoacoustic and surface-enhanced Raman spectroscopies. Phys. Chem. Chem. Phys. 2015, 17, 21190-21197. [CrossRef]

55. Hunter, C.A.; Sanders, J.K.M. The Nature of $\pi-\pi$ Interactions. J. Am. Chem. Soc. 1990, 112, 5525-5534. [CrossRef]

56. Péron, O.; Rinnert, E.; Toury, T.; Lamy de la Chapellec, M.; Compèrea, C. Quantitative SERS sensors for environmental analysis of naphthalene. Analyst 2011, 136, 1018. [CrossRef] [PubMed]

57. Xuegang Gong, X.; Liao, X.; Li, Y.; Cao, H.; Zhao, Y.; Lia, H.; Cassidyc, D.P. Sensitive detection of polycyclic aromatic hydrocarbons with gold colloid coupled chloride ion SERS sensor. Analyst 2019, 144, 6698. [CrossRef] [PubMed]

58. Xu, Y.; Zhong, P.; Jiang, A.; Shen, X.; Li, X.; Xu, Z.; Shen, Y.; Sun, Y.; Lei, H. Raman spectroscopy coupled with chemometrics for food authentication: A review. Trends Anal. Chem. 2020, 131, 116017. [CrossRef]

59. Zhou, H.; Li, X.; Wang, L.; Liang, Y.; Jialading, A.; Wang, Z.; Zhang, J. Application of SERS quantitative analysis method in food safety detection. Rev. Anal. Chem. 2021, 40, 173-186. [CrossRef] 